\title{
Adaptability Assessment and Analysis of Temporal and Spatial Differences of Water-Energy-Food System in Yangtze River Delta in China
}

\author{
Zichen Han $^{1}$ and Hailiang Ma ${ }^{2, *(D)}$ \\ 1 Department of International Economics and Trade, Business School of Hohai University, \\ Changzhou 213022, China; zichenhan954@gmail.com \\ 2 Department of Business Management, Business School of Hohai University, Changzhou 213022, China \\ * Correspondence: mahl@hhu.edu.cn
}

check for

updates

Citation: Han, Z.; Ma, H.

Adaptability Assessment and

Analysis of Temporal and Spatial

Differences of Water-Energy-Food

System in Yangtze River Delta in

China. Sustainability 2021, 13, 13543.

https://doi.org/10.3390/su132413543

Academic Editors: Riccardo Testa,

Giuseppina Migliore,

Giorgio Schifani and József Tóth

Received: 15 October 2021

Accepted: 3 December 2021

Published: 7 December 2021

Publisher's Note: MDPI stays neutral with regard to jurisdictional claims in published maps and institutional affiliations.

Copyright: (C) 2021 by the authors. Licensee MDPI, Basel, Switzerland. This article is an open access article distributed under the terms and conditions of the Creative Commons Attribution (CC BY) license (https:// creativecommons.org/licenses/by/ $4.0 /)$.

\begin{abstract}
Serving as an effective tool for research on regional sustainable development, adaptive management has become the subject of global climate change and environmental economic research nowadays. Based on the perspective of the adaptability of the composite system, this article decomposes the adaptability into four aspects: sensibility, stability, compatibility and sustainability. We use the pressure-state-impact-response (PSIR) model to construct a Comprehensive Index Evaluation System for the adaptability of the Water-Energy-Food System in the Yangtze River Delta from 2010 to 2019. Our analyses show that: Firstly, the adaptability of the Water-Energy-Food System in the Yangtze River Delta fluctuates greatly, with the lowest value being only 33.35\% of the highest value. Secondly, while sensibility shows an "M-shaped" development trend, the stability, sustainability and compatibility of the Water-Energy-Food System in the Yangtze River Delta changes simultaneously, showing a "U-shaped" development trend as a whole. Thirdly, there exists significant spatial differences in the adaptability of the Water-Energy-Food System in the Yangtze River Delta. Zhejiang Province has the highest level of system adaptability, while Anhui Province has the lowest. Based on that, we recommend to strengthen the coordinated management of various departments and natural resources in the Yangtze River Delta and implement strict red lines for resource utilization and environmental protection.
\end{abstract}

Keywords: Water-Energy-Food System; adaptability assessment; PSIR model; time-space differentiation

\section{Introduction}

Water, energy and food resource are basic resources for human survival and development. Water, energy and food systems are all components of the natural resource system, being promoted and restricted in relation with each other. In 2011, Bonn Conference in Germany first put forward the concept of the "Water-Energy-Food" link (the Water-EnergyFood System Nexus), clarifying the importance of the Nexus between water, energy and food systems. Currently, the global environment is deteriorating and the impact of climate change is intensifying, problems including shortage of fresh water [1], volatile food supply and growing energy demand in China are becoming increasingly serious. It is an urgent need to assess the adaptability level of the Water-Energy-Food System and improve the utilization efficiency of resources is an important part of the transition from "single resource" management to "multi-resource" comprehensive management. In this way, China will achieve the green and coordinated development, which has enormous practical significance and social value. With the enrichment of research methods, scholars have extended their research perspectives to the external connection between the Water-Energy-Food System and the Socio-economic system based on the internal connection of natural systems. Besides, researchers also introduce the concepts of ecosystem, sustainable development [2] 
and adaptive management to further improve the theoretical system of research on WaterEnergy-Food System. The Yangtze River Delta is the most economically developed and densely populated area in China. Compared with huge demand in the Yangtze River Delta, the relative scarcity of basic resources, including energy and food resources, has brought more security risk to economic development and people's livelihoods. Therefore, analyzing the internal coordination of water, energy and food systems in the Yangtze River Delta and evaluating the adaptability of the Water-Energy-Food System to external social systems is important in the transition from single-resource management to multi-resource integrated management. It is of great value to regional integrated development of the Yangtze River Delta and resource security strategy.

Concepts of adaptability first appeared in the field of climate change [3]. It mainly describes the process of the subject's continuous adaptation and evolution [4] in the stimulus-response model of the environment. At present, concepts of adaptability have been generally recognized [5,6]. Many major scientific programs around the world have adopted adaptability as an important criterion for mankind to cope with climate changes [7]. At the same time, countries have formulated a series of national strategies based on the adaptability. They have carried out fruitful practice and explorations [8] in fields including management of adaptive risks [9] and policy planning of industry sectors [10]. Maibritt Pedersen Zari [11] and Wan Wenjie [12], etc. combined social systems, economic systems, and natural systems to study the adaptability of complex ecosystems. They believed that the exchange processes of material, information and energy in its internal subsystems conform to the basic laws of the ecosystem. Under the background of complex ecosystems research, Gonçalves Catarina [13], Hoyoung Jeong [14] and Li Bo [15] further studied the adaptability between the socio-economic system and the environmental ecosystem on the basis of previous researches. Li Bo introduced the concept of adaptability into the marine ecosystem and deeply studied the adaptability between the human-sea economic system and the environmental system. In general, currently research scopes concerning adaptability extend from adaptability of natural system to adaptability [16] of ecological-economic composite systems. Adaptation goals has shifted from harm-avoiding adaptation [17] to profit-oriented adaptation [18]. The adaptation mechanism changes from passive adaptation [19] to active adaptation. The adaptation timeliness has been extended from emergency adaptation [20] to medium and long-term adaptation [21]. Adaptability has become the critical research direction of global geography [22], ecology [23], environmental science [24] and other related disciplines.

Considering the Water-Energy-Food System, there are relatively few studies focusing specially on the adaptability. In particular, they pay little attention to the external economic and social environment of the Water-Energy-Food System. It fails to reflect the initiative and complexity of the interaction between the adaptive subjects and the external environment. Based on this, we introduce the Complex Adaptive Systems Theory into the Water-Energy-Food System and construct a PSIR model of Natural System and Socioeconomic System. Through the Comprehensive Index Evaluation System of adaptability, this paper systematically evaluates the adaptability of the Yangtze River Delta the WaterEnergy-Food System from 2010 to 2019. Finally, we try to provide policy recommendations for the adaptive optimization of the Water-Energy-Food System in the Yangtze River Delta, in expectation of promoting regional sustainable development.

\section{Theoretical Analysis of the Adaptability of the Water-Energy-Food System}

Holland [25] defines the complex adaptive system as a system composed of interactive adaptive subjects described by rules. These subjects continue to learn and accumulate experience, thus continuously changing their rules, structure and behavior. They actively learn from outside and form feedback signals, constantly adapting to the changing environment. The water system, energy system, and food system follow stimulus-response rules in the interaction with environment as three independent adaptable subjects. In this way, they are generally optimizing their own structure and enhancing the ability to adapt to external 
environment in the evolution. As a result, a new composite system will come into being, namely the Water-Energy-Food System.

From the perspective of system theory, the adaptive evolution process of the WaterEnergy-Food System conforms to the pressure-state-impact-response model, namely the PSIR model. We can analyze the connotation and mechanism of adaptability of the WaterEnergy-Food System through it. As is shown in Figure 1, when the external environment continues to evolve, disturbance factors, such as the epidemic and resource shortage, hit the Socio-economic Stress Subsystem. Then this leads to Socio-economic Stress Subsystem forcing pressure on Natural Resource State Subsystem. In this process, many factors of Natural Resource Impact Subsystem, such as food supply and water quality, changes the original equilibrium state of supply and demand, negatively affected by the outside. This has a negative influence on the utilization and protection of natural resource, causing the deterioration of the Natural Resource Impact Subsystem. Faced with a large number of undesirable outputs in the production, people begin to reflect and adopt technical measures, administrative measures or market adjustment measures to improve the stability of the Water-Energy-Food System. The implementation of water conservancy engineering, agricultural industry and energy engineering has improved the state of the natural resource subsystem. Obviously, it promotes the emergence of benign results such as the reduction in carbon dioxide emissions and ecological restoration.

In order to scientifically evaluate the adaptability of the Water-Energy-Food System, borrowing from adaptability concepts proposed by Yanling Zhi [26] from Symbiosis Theory, we propose the definition of adaptability of the Water-Energy-Food System: in the socioeconomic-natural composite system, water, energy, and food systems form a coordinated, matched, and adaptive relationship during the entire life cycle of resource exploitation and utilization. The interactive relationship can optimize resource allocation and improve resource utilization efficiency, thus increasing the output benefits of the entire composite system. In this process, the external socio-economic system and natural system achieve coordination and symbiosis. The Water-Energy-Food System adapt with each other and enter a relatively coordinated and stable state in the process of balancing the contradiction between supply and demand. Then pollutant emission and unintended output will decline and the green and coordinated operation of the Water-Energy-Food System will be sustainable, which ensures the high-quality development of the regional economy. We can analyze the characters and laws of the Water-Energy-Food System based on the microscopic view of the system interior. We select multiple indicators of the water, energy, and food system as the dynamic factors of the system evolution model. The entropy weight method is employed to determine the influence coefficients among microscopic factors. Through this way can we realize the cyclic feedback between the local model and the global model and fully present the complexity and adaptability of the evolution process of the complex giant system. 


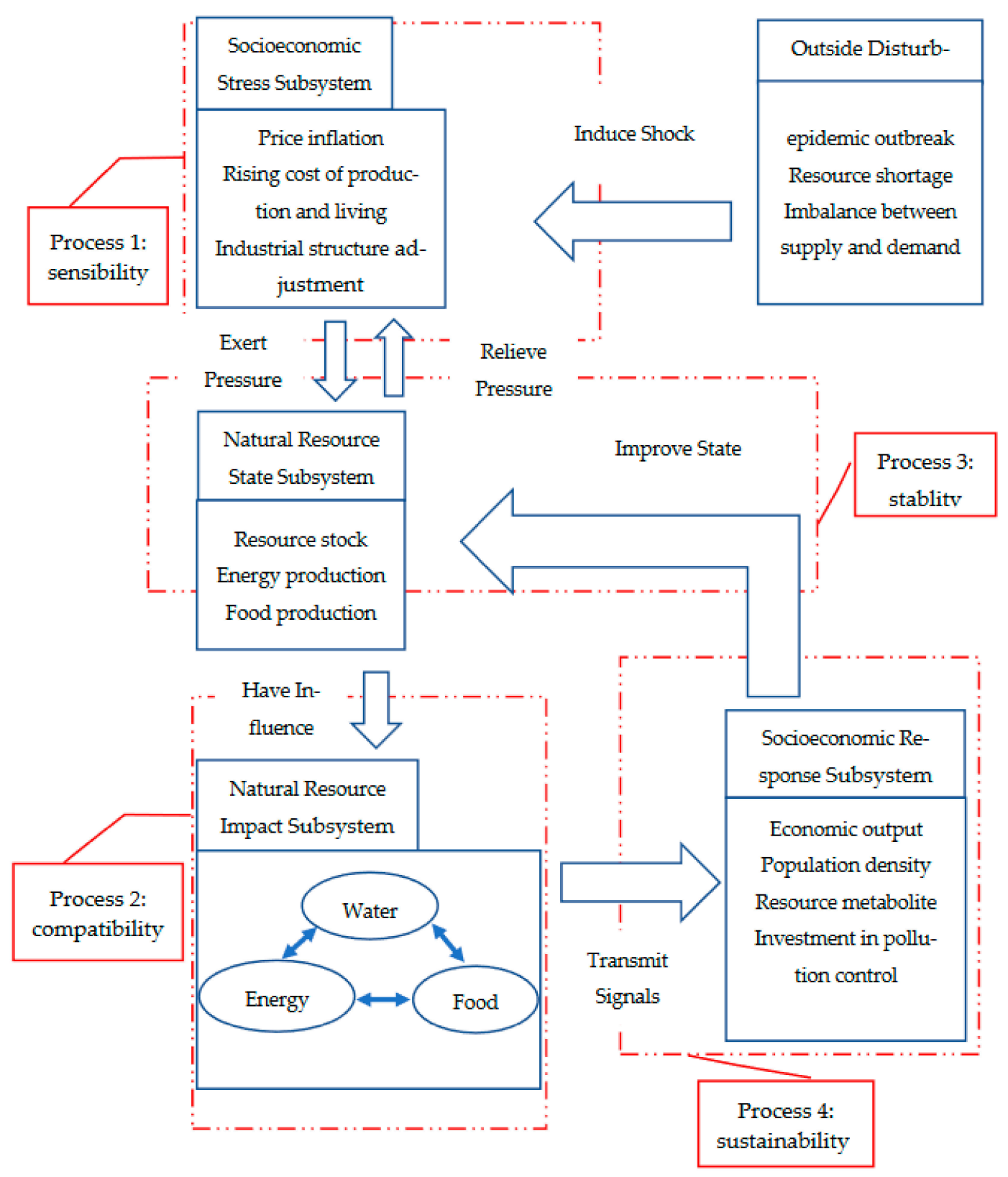

Figure 1. PSIR model.

3. Construction of a Comprehensive Index Evaluation System for the Adaptability of the Water Resources-Energy-Food System

3.1. System Design of Evaluation Indicators

3.1.1. Criterion Level-Element Level-Index Level Analysis

Based on theoretical analysis of the adaptability of the Water-Energy-Food System, we decompose the adaptability into four aspects: sensibility (F), stability (S), compatibility (C) and sustainability $(\mathrm{E})$.

Sensibility is also called vulnerability or anti-interference performance. It means that a certain part of the system will cause other parts to change in a short period. It also reflects the extent to which the Water-Energy-Food System is subject to potential or apparent stress from the external environment. Corresponding to process 1 in the figure, under the influence of external disturbance, Socio-economic Stress Subsystem exerts pressure on Natural Resource State Subsystem.

Compatibility describes the convergence of changes between different objects. It reflects the matching degree of the elements of the Water-Energy-Food System and mea- 
sures the efficiency of resource allocation and utilization in the transformation process. Corresponding to process 2 in the figure, influenced by Natural Resource State Subsystem. The interior of Natural Resource Impact Subsystem is composed of water, energy, and food, interrelated and restricted with each other. They commonly coordinate the operation of the Water-Energy-Food System and promote the sustainable development of the Natural System.

The stability reflects the capacity of the Water-Energy-Food System to absorb outside interference and sustain its original state when the internal and external environment changes. Corresponding to process 3 in the figure, the Socio-economic Response Subsystem feeds back signals to the Natural Resource State Subsystem, causing positive improvement. It counteracts the Socio-economic Stress Subsystem and largely alleviates the initial imposed pressure. Through self-regulation of system, the external socio-economic system and internal natural system are kept in a relatively stable state, which reflects the stability of the Water-Energy-Food System.

The sustainability refers to the process in which the Water-Energy-Food System maintains for a long time. It reflects the potential ability of the Water-Energy-Food System to develop steadily and keep the state close to the original level in the future. It also measures the adaptability and effect of interaction between the Natural System and Socio-economic System. In the PSIR model, transmission mechanism of signals circulates and reflects the relevance and sustainability of the external socio-economic system and the internal natural system, promoting sustainable development of the Water-Energy-Food System.

According to the classic theory of adaptability, adaptability mainly means that under the influence of external interference, the composite system coordinates with each other, and maintain a stable state. In this way, can this system continuously adapt to external changes, and finally achieve sustainable development. Existing literature generally studies adaptability in terms of sensitivity, coordination, stability and sustainability. Following the research ideas of adaptability theory, the paper studies the adaptability of WaterEnergy-Food System of Yangtze River Delta in China on the basis of such four dimensions including sensitivity, compatibility, stability and sustainability. Based on the subjects of the Water-Energy-Food System, studies of sensitivity and stability are all based on criterion layers including the water, energy and food systems. Compatibility refers to the degree of coupling and matching between multiple systems, therefore the water-energy, water-food, and energy-food system are determined as the criterion level. Moreover, sustainability refers to the system performance of the long-term maintenance and the potential ability to balance the future development through adjustments, it is equipped with the ability to protect the ecological environment and guarantee the improvement of people's living standards, at the same time of promoting economic development.

Based on the PSIR model, we analyze adaptability and indicators considering indicators used in relevant [27] studies [28]. Following the principles of scientificity, dynamics, data availability and hierarchy, we deeply analyse the adaptability of Water-Energy-Food System of Yangtze River Delta in China from four dimensions including sensitivity, compatibility, stability and sustainability, on which we based our selection of representative indicators belonging to respective criterion layers to explore the evolutionary law of adaptability. As for sensibility, we choose water, energy and the food system as the element layers and select 11 indicators such as groundwater resources utilization and energy foreign dependence. As for compatibility, we use Water-Energy System (WE), Water-Food System (WF) and Energy-Food System (EF) as the element layers, and select 12 indicators such as energy consumption of water system and food production. As for stability, water system (SW), energy system (SE) and food system (SF) are used as the element layers, and 12 indicators are selected, such as the amount of water per capita. As for sustainability, the economic system, social system and natural system are used as the element layer, and 20 indicators such as population density and urbanization rate are chosen. The weight of corresponding system and indicators can be calculated with the entropy method. 


\subsubsection{Weight Determination and Data Sources}

Firstly, select the index data from 2010 to 2019 in the yearbook and convert the indicators of different dimensions into the same dimension. We use the TOPSIS method to standardize the logarithm and calculate the weight of each index according to the entropy weight method. The calculation formula is as follows.

$$
\begin{gathered}
P_{i j}=\frac{Z_{i j}}{\sum_{i=1}^{n} Z_{i j}} \\
k=\frac{1}{\ln n} \\
E_{i}=-k \sum_{j=1}^{n}\left(P_{i j} \ln P_{i j}\right) \\
W_{i}=\frac{1-E_{i}}{\sum_{i=1}^{m}\left(1-E_{i}\right)}
\end{gathered}
$$

$P_{i j}$ indicates the proportion of sample $j$ of index $i$ in the index. It is a collection of all indicators, namely $x_{i j}$. In the Comprehensive Index Evaluation System for the adaptability of the Water-Energy-Food System, $m$ indicates that there are $m$ indicators. $n$ Indicates that each indicator has $\mathrm{n}$ sample value. $\omega_{i j}$ indicates the weight of the index.

The formula for calculating the score of the sample using the weighted sum formula is as follows. Since both P and W are decimals between $0-1$, they are enlarged by 100 times in order to facilitate the comparison of data results.

$$
S=\sum_{j} 100 P_{i j} \omega_{i j}
$$

3.1.3. Calculation Results of the Comprehensive Index Evaluation System for the Adaptability of the Water-Energy-Food System

According to obtained indicators and calculated weights of three systems and elements, a Comprehensive Index Evaluation System for the adaptability of the Water-Energy-Food System based on the TOPSIS method is established. Set $x^{\alpha}=(1,1, \cdots, 1)$ as the "ideal solution" of the Comprehensive Index Evaluation System and $x^{\beta}=(0,0, \cdots, 0)$ as the "negative ideal solution" of the evaluation system. Euclidean distance $d\left(x_{i}, x^{\alpha}\right)=\sqrt{\sum_{j=1}^{n} \omega_{j}^{2}\left(x_{i j}-x_{j}^{\alpha}\right)^{2}}$ is the distance from $x_{i}$ to the "ideal solution". $d\left(x_{i}, x^{\beta}\right)=\sqrt{\sum_{j=1}^{n} \omega_{j}^{2}\left(x_{i j}-x_{j}^{\beta}\right)^{2}}$ is the distance from $x_{i}$ to the "negative ideal solution". Establish a Comprehensive Index Evaluation Function as follows.

$$
F=\frac{1}{1+\left(\frac{d\left(x_{i}, x^{\alpha}\right)}{d\left(x_{i}, x^{\beta}\right)}\right)^{2}}
$$

Among them, $x_{i j}$ represents the standardized index value. $0 \leq F \leq 1, i=1,2, \cdots, m$. The larger $F$ is, the better the evaluation result will be. Calculate the adaptability of the Water-Energy-Food, as well as sensibility (F), stability index (S), compatibility index (C) and sustainability index (E). The Comprehensive Index Evaluation System for the adaptability of the W-E-F System is shown in Table 1. 
Table 1. Comprehensive Index Evaluation System for the adaptability of the W-E-F System.

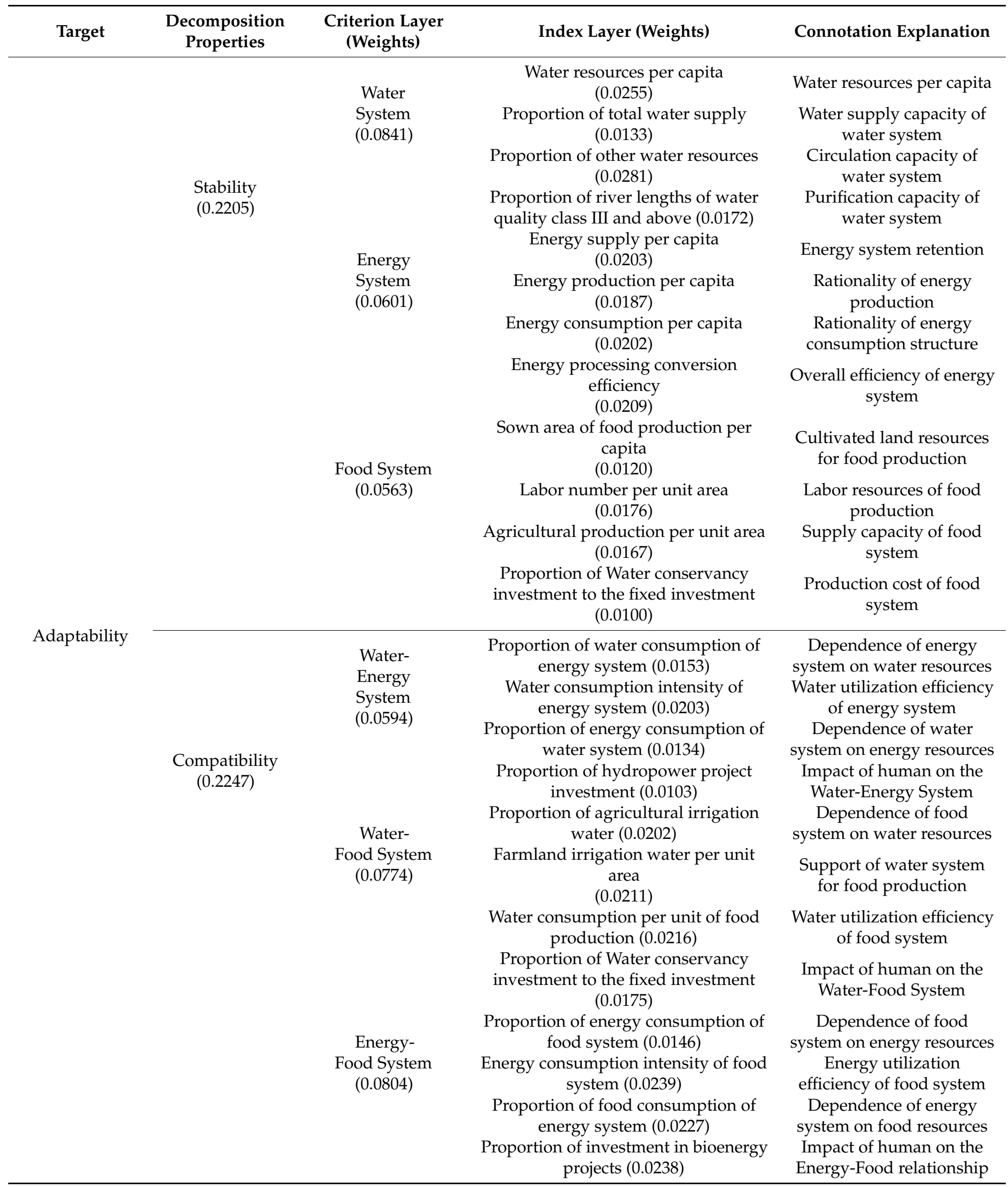


Table 1. Cont.

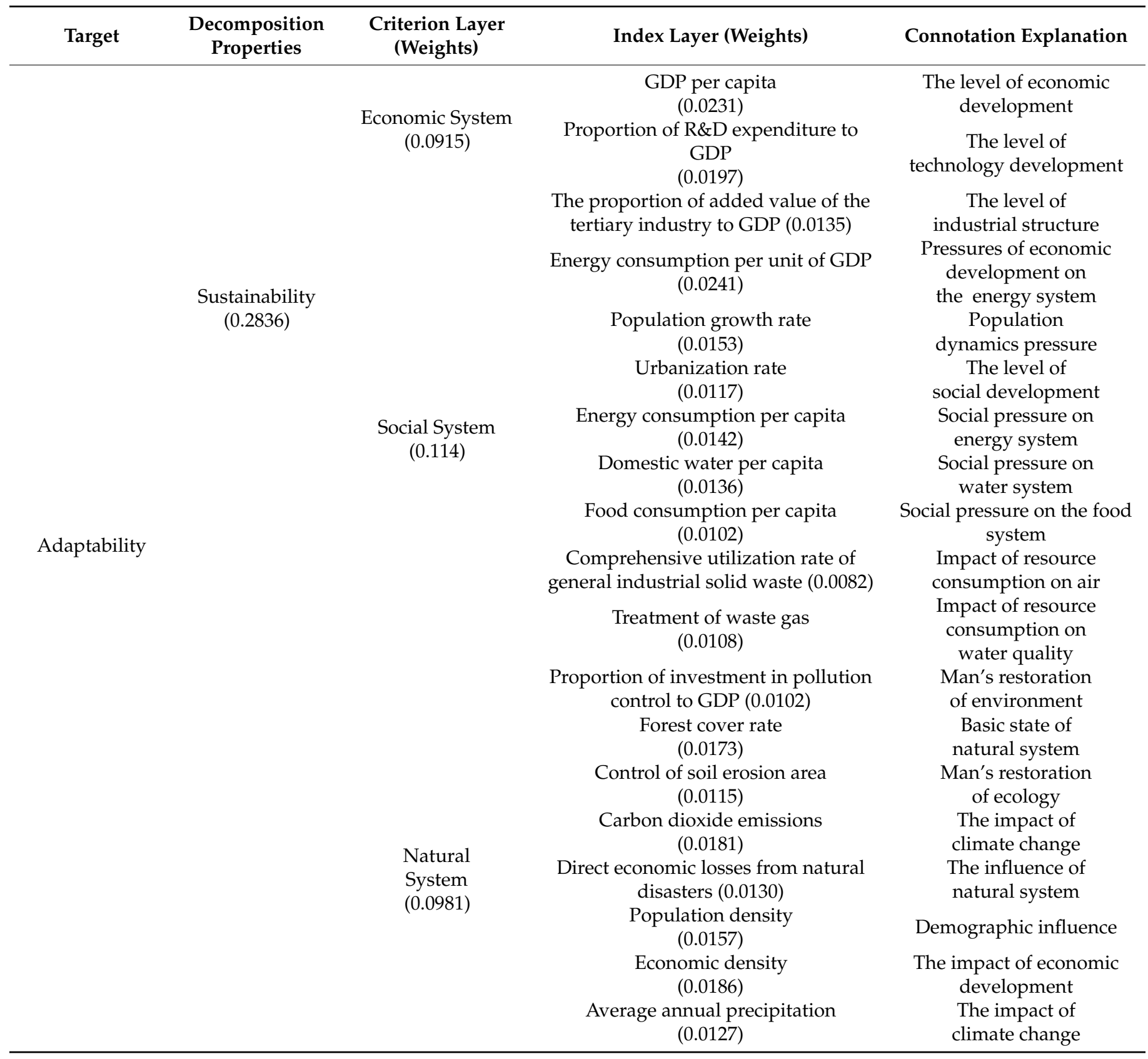


Table 1. Cont.

\begin{tabular}{|c|c|c|c|c|}
\hline Target & $\begin{array}{l}\text { Decomposition } \\
\text { Properties }\end{array}$ & $\begin{array}{l}\text { Criterion Layer } \\
\text { (Weights) }\end{array}$ & Index Layer (Weights) & Connotation Explanation \\
\hline \multirow{19}{*}{ Adaptability } & \multirow{19}{*}{$\begin{array}{l}\text { Sensibility } \\
(0.2712)\end{array}$} & \multirow{6}{*}{$\begin{array}{l}\text { Water Sensibility } \\
\quad(0.0870)\end{array}$} & Average annual precipitation & The impact of climate \\
\hline & & & $(0.0273)$ & change \\
\hline & & & Utilization rate of groundwater & The safety of \\
\hline & & & $(0.0105)$ & groundwater system \\
\hline & & & Sewage discharge per unit of GDP & The impact of resource \\
\hline & & & $(0.0264)$ & $\begin{array}{l}\text { consumption on } \\
\text { water quality }\end{array}$ \\
\hline & & \multirow{9}{*}{$\begin{array}{c}\text { Energy } \\
\text { Sensibility } \\
(0.0982)\end{array}$} & $\begin{array}{c}\text { Treatment of wastewater } \\
(0.0228)\end{array}$ & Man's improvement of life \\
\hline & & & Energy dependence on foreign & \\
\hline & & & resources & $\begin{array}{l}\text { vuinerabillty or energy } \\
\text { system }\end{array}$ \\
\hline & & & $\begin{array}{l}\text { (0.0293) } \\
\text { Dromention }\end{array}$ & \\
\hline & & & $\begin{array}{l}\text { Proportion of added value of the } \\
\text { secondary industry to GDP0.0294 }\end{array}$ & $\begin{array}{l}\text { The level of } \\
\text { industrial structure }\end{array}$ \\
\hline & & & SO2 emissions per unit of GDP & The impact of resource \\
\hline & & & $(0.0104)$ & consumption on air \\
\hline & & & Completed investment of industrial & Man's restoration \\
\hline & & & pollution control $(0.0291)$ & of environment \\
\hline & & \multirow{4}{*}{$\begin{array}{c}\text { Food } \\
\text { Sensibility } \\
(0.0860)\end{array}$} & Proportion of the added value of & The level of \\
\hline & & & primary industry to GDP $(0.0384)$ & industrial structure \\
\hline & & & $\begin{array}{l}\text { Agricultural production material price } \\
\text { index }(0.0163)\end{array}$ & $\begin{array}{l}\text { Production cost of } \\
\text { food system }\end{array}$ \\
\hline & & & $\begin{array}{l}\text { Food dependence on foreign resources } \\
\qquad(0.0313)\end{array}$ & $\begin{array}{l}\text { Vulnerability of } \\
\text { food system }\end{array}$ \\
\hline
\end{tabular}

The research area of this article is the Yangtze River Delta region. All data comes from China Statistical Yearbook, China Energy Statistical Yearbook, China Rural Statistical Yearbook, China Environment Statistical Yearbook, China Water Resources Bulletin and China Water Conservancy Statistical Yearbook from 2010 to 2019.

\section{Empirical Analysis}

4.1. The Temporal Evolution of Adaptability of the Water-Energy-Food System in the Yangtze River Delta

According to Formula (6), we calculated the adaptability of the Water-Energy-Food System in the Yangtze River Delta from 2010 to 2019. The changes are shown in the histogram in Figure 2. It can be seen from the figure that the adaptability of the WaterEnergy-Food System in the Yangtze River Delta fluctuates greatly from 2010 to 2019. The level of adaptability hovered at a low level from 2015 to 2017, reaching a trough of 0.2665 in 2015. The reason for this phenomenon is that Jiangsu Province was hit by a superhistorical heavy rainstorm in 2015. The rainfall and water levels exceeded historical levels in economically developed areas such as southern Jiangsu. The Water-Energy-Food System in the Yangtze River Delta was subjected to certain external shocks, and the stability level declined sharply. Besides, the State Council of China issued the "Three-Year Action Plan for Winning the Blue Sky Defense War" in 2018 and required to reduce the total emissions of major air pollutants after three years' efforts. This can synergistically reduce greenhouse gas emissions and improve ambient air quality. At the same time, the "river chief system" begun to be fully implemented in the Yangtze River Delta, which requires the government to strengthen water environment governance and raise water resource utilization efficiency. Therefore, the adaptability of the Water-Energy-Food System in the Yangtze River Delta has been significantly improved, reaching a relatively high level during the research period. 


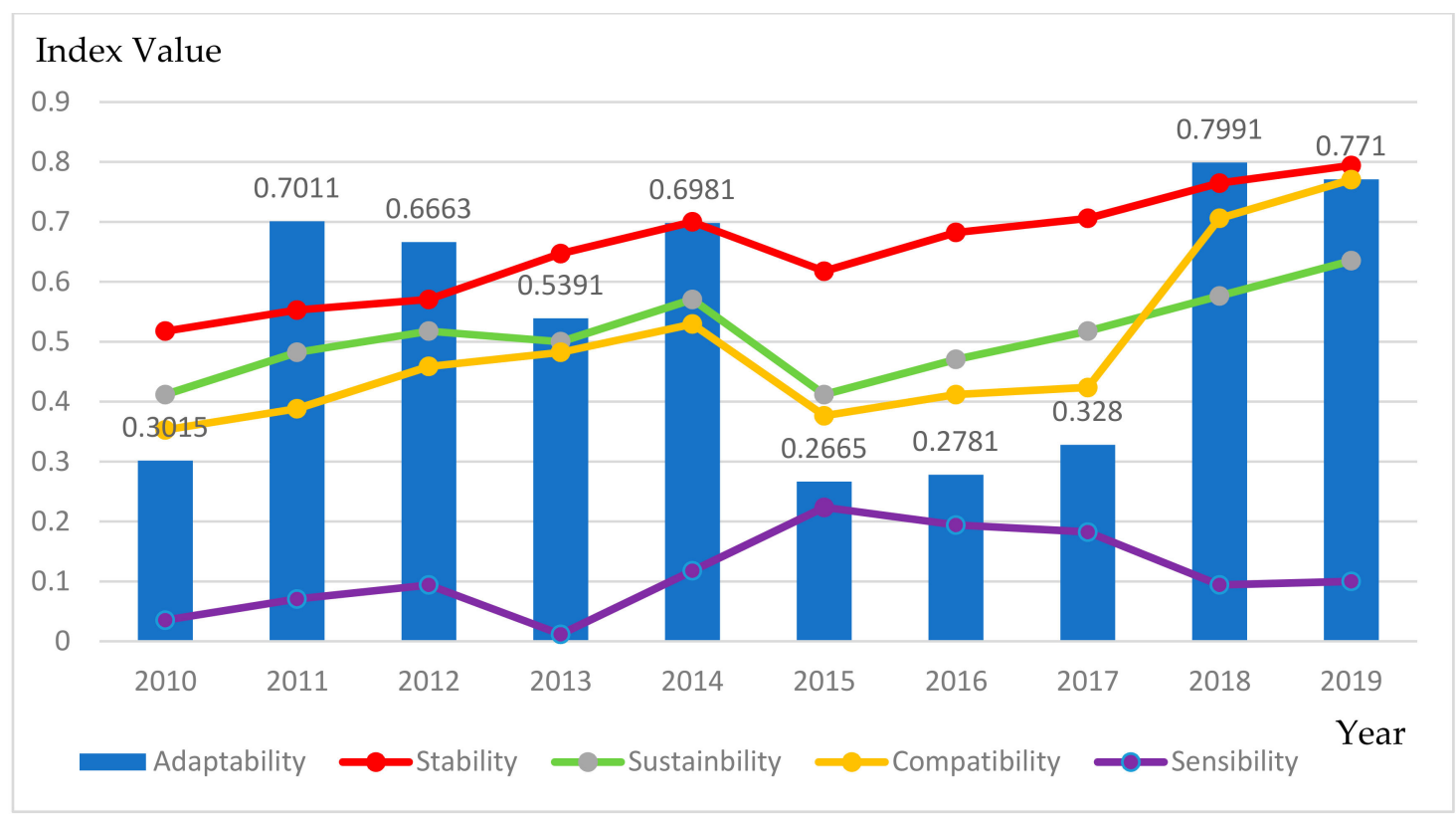

Figure 2. Time series of adaptation and decomposition effects of Yangtze River Delta from 2010 to 2019.

We decomposed the adaptability of the Water-Energy-Food System, as shown in the broken line chart in Figure 2. We can find that the stability, sustainability, and compatibility during the period changes synchronously, with the " $U$ " development trend. By contrast, the sensibility presents the " $\mathrm{M}$ " development trend. The concrete analysis is as follows.

\subsubsection{Stability Analysis of the Water-Energy-Food System}

The stability of the Water-Energy-Food System has remained at high levels throughout the years, reaching its trough at 0.52 in 2010 and its peak at 0.79 in 2019. Although, the Water-Energy-Food System was shocked by the Socio-economic System in 2015, the sensibility still reached 0.22 . This fully demonstrates that the water, energy and food system in the Yangtze River Delta can maintain a stable state facing internal and external environmental changes. The main reasons can be divided into three aspects. Firstly, the Yangtze River Delta is rich in natural resources, involving water and mineral resource. The Yangtze River Delta is always China's granary and the engine of economic development. Therefore, the Water-Energy-Food System in the region can adjust itself steadily and adapt to the external economic system. Secondly, as one of the most economically developed regions in China, there are a large number of enterprises whose main business is the utilization and trading of various natural resources in the Yangtze River Delta. They can make full use of market mechanisms and price methods to eliminate hidden risks in the Water-Energy-Food System. In addition, the Yangtze River Delta has convenient transportation. Ningbo Port, Shanghai Port and Suzhou Port are among the top ten ports in the world in terms of throughput, let alone dense airport routes and high-speed rail lines. These contributing factors can ensure that the region quickly transport resource elements from other regions, thus stabilizing the Water-Energy-Food System.

\subsubsection{Sustainability Analysis of the Water-Energy-Food System}

During the study period, the sustainability of the Water-Energy-Food System in the Yangtze River Delta fluctuated violently. Before 2014, the sustainability of the Water-EnergyFood System increased slowly, rising from 0.41 in 2010 to 0.57 in 2014 . However, due to the external impact of natural disasters in 2015, the sustainability plummeted sharply, hitting the bottom at 0.41. It began to show shows a trend of slow rise in 2016. On the whole, the Water-Energy-Food System in the Yangtze River Delta was in a "U-shaped" development trend during the study period. This indicates that except influencing factors 
like extreme natural disasters, the Water-Energy-Food System in the Yangtze River Delta maintained a stable development state generally. This is mainly because the Yangtze River Delta is located in the lower reaches of the Yangtze River, the third largest river in the world, with abundant water resources, annual average precipitation over $1000 \mathrm{~mm}$. At the same time, the Yangtze River Delta is the traditional hometown of rice and freshwater fish in China, with a high agricultural output. In addition, as one of the most economically developed regions in China, the Yangtze River Delta, has a number of important economic and technological development cities such as Shanghai, Hangzhou and Nanjing. These factors provide good conditions for the interaction between the Water-Energy-Food System and the economic and social system.

\subsubsection{Compatibility Analysis of the Water-Energy-Food System}

Compared with sensibility and sustainability, the compatibility of the Water-EnergyFood System in the Yangtze River Delta is obviously low. Except for 2014, 2018 and 2019, the compatibility did not exceed 0.5. This fully shows that the Yangtze River Delta did not maintain a synchronized development trend among Water-Energy Systems, WaterFood Systems and Energy-Food Systems. Three systems including water, energy and food systems did not achieve coupling and symbiotic development. Therefore, from the perspective of multi-resources integration, it is particularly important to carry out researches on the coordination of the Water-Energy-Food System Nexus and strengthen cooperation between departments. From the perspective of the development trend, the coordination of the Water-Energy-Food System in the Yangtze River Delta presents a typical "U-shape" development trend. Except for 2015-2017, compatibility showed an overall upward trend. This also indicates that in recent years, under the background of the national strategy of the integration of the Yangtze River Delta, the Yangtze River Delta has strengthened the internal collaborative management of natural resources through a large number of water conservancy projects, agricultural high-efficiency demonstration area projects and photovoltaic new energy projects to enhance the compatibility of the Water-Energy-Food System and. increase system adaptability steadily.

\subsubsection{Sensibility Analysis of the Water-Energy-Food System}

The Water-Energy-Food System in the Yangtze River Delta fluctuates violently in sensibility, with the overall development trend " $\mathrm{M}$ ". According to the results of data analysis, two peaks occurred in 2012 and 2015, 0.1 and 0.23 respectively, but both did not exceed 0.3. The data values of two troughs in 2010 and 2013 are also relatively small, both less than 0.05. However, the analysis shows that sensibility is a negative index and the smaller the index data value, the lower the degree of stress the system receives from the external environment. Therefore, this fully indicates that the negative impact is generally controllable although the Water-Energy-Food System in the Yangtze River Delta is often randomly shocked by changes in the economic, social and environmental systems. As one of China's most economically developed area, the Yangtze River Delta has a relatively sound price transmission mechanism and market transaction system. Besides, its characteristics of the external economy are more obvious. The allocation of resource elements can be carried out from the all-factor market, so it is difficult to cause the hidden danger of insufficient supply of resource elements. This also led to relatively low index values such as dependence on foreign energy. Even during the COVID-19 pandemic, the global shortage of food and energy supplies did not cause a major blow to the WaterEnergy-Food System in the Yangtze River Delta, with the sensibility index controlled at around 0.1 .

\subsection{Spatial Variation of Adaptability of the Water-Energy-Food System in the Yangtze River Delta}

The index values of each region in the Yangtze River Delta from 2010 to 2019 are calculated through Formula (6) and the average value is taken. The comparative analysis is as follows. 
As can be seen from Figure 3, Shanghai, Jiangsu, Zhejiang and Anhui have significant differences in the adaptability of the Water-Energy-Food System. Among them, Zhejiang Province has the highest level, reaching 0.8605, which exceeds the overall level of the Yangtze River Delta by about $4.94 \%$. This shows that Zhejiang's Water-Energy-Food System develops best, equipped with the strongest ability to adapt to changes in the external environment. This reflects the mutual promotion and joint development between the resource environment system and the social economic system. Besides, the adaptability levels of Jiangsu and Shanghai are relatively close to the average level of the Yangtze River Delta. It indicates that their system development state is relatively stable for many years. By contrast, Anhui' adaptability is the lowest, lower than $13.71 \%$ of the overall level in the Yangtze River Delta. This shows that the performance of the Water-EnergyFood System in Anhui is relatively poor. Its adaptability and compatibility to social and economic development are relatively low. It's necessary to strengthen macro policy control and optimize resource allocation to raise utilization efficiency and promote coordinated development of the Water-Energy-Food System.

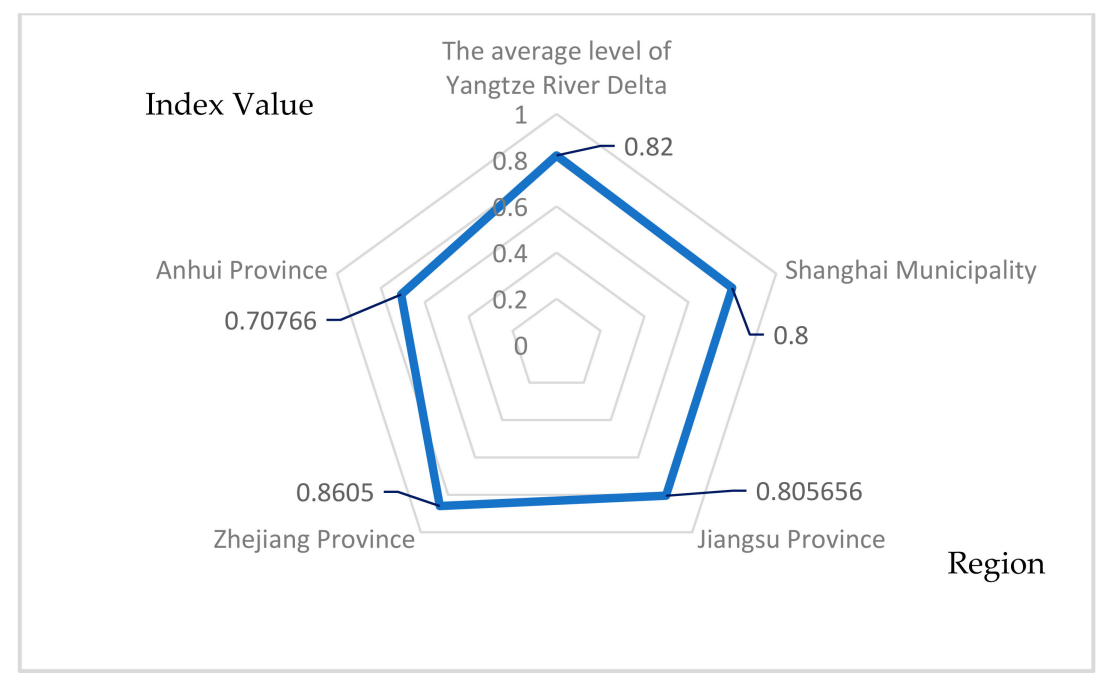

Figure 3. Average adaptability of regions in the Yangtze River Delta from 2010 to 2019.

We quantitatively analyse the average level of sensibility, sustainability, compatibility and stability of various regions in the Yangtze River Delta from 2010 to 2019. As shown in Figure 4, we found that these features also have significant spatial differences.

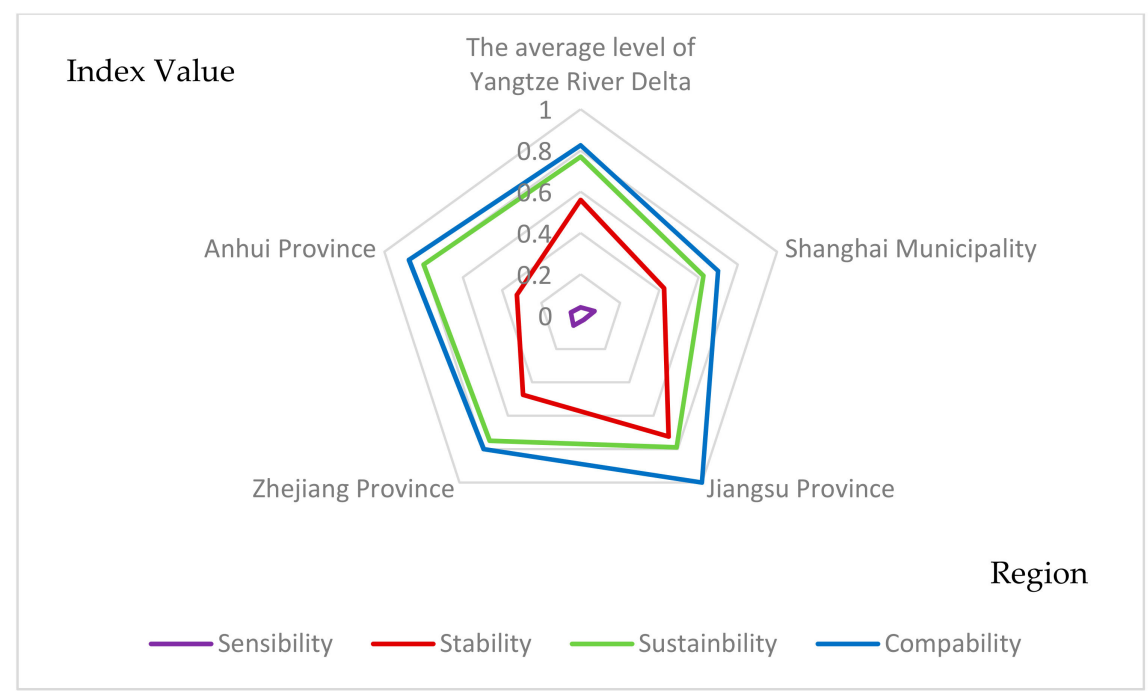

Figure 4. Adaptive decomposition diagram of regions in the Yangtze River Delta from 2010 to 2019. 
For Shanghai, the stability, sustainability and compatibility of the Water-Energy-Food System are at a relatively low level. On the contrary, the sensibility level is the highest among all regions. Shanghai is one of the most important economic and financial centers in China, but its natural resources are relatively insufficient. In fact, Shanghai has high reliance on foreign resources and almost all energy for industrial production and food needed for daily life depend on imports. In addition, Shanghai's leading industries are electronics manufacturing, petrochemical and fine chemical manufacturing, and biomedical manufacturing. These industries have higher requirements for the purity of water resources and the stability of electricity. This also led to the weakness of Shanghai 's Water-EnergyFood System in resisting external interference and attacks.

Jiangsu' compatibility and stability is the strongest among all regions in the Yangtze River Delta. In the element layer, the Energy-Food System and Water System contribute most. Besides, the energy consumption intensity of the agricultural system and other water resource account for the highest proportion. In recent years, Jiangsu has continuously promoted agricultural modernization, strengthened agricultural technology and equipment support and increased the level of improved agricultural varieties, thus advancing the development of the Water-Energy-Food System.

For Zhejiang, the sustainability and stability of the Water-Energy-Food System has been kept at a relatively high level, which has made significant contributions to the further consolidation and improvement of Zhejiang's environmental adaptability. However, the level of compatibility in Zhejiang is relatively low, ranking second to last among all regions in the Yangtze River Delta. Obviously, it is the shortcoming of further development of Zhejiang' Water-Energy-Food System. The reason is that Zhejiang's energy consumption intensity of the agricultural system, food consumption of the energy system and bio-energy project investment are relatively low. This also indicates that Zhejiang needs to coordinate the internal relationship between energy system and food system to promote cross-regional flow of elements and optimize resource allocation. Besides, expanding investment in technology and capital is necessary to promote the coordinated and efficient development of water, energy and food systems.

Anhui' stability of the Water-Energy-Food System ranks last among the regions of the Yangtze River Delta, which is the main reason for the weakest adaptability of Anhui Province. Elements of Water System are the key factors restricting the improvement of the stability. Furthermore, the water resource per capita and the proportion of other water resources in the Water System have a greater impact on the enhancement of the WaterEnergy-Food System compared with other elements. Anhui Province is one of the important agricultural regions in China. However, large inter-annual changes in precipitation and frequent floods and droughts directly influence food production and energy extraction, aggravating the instability and uncertainty of the Water-Energy-Food System.

\section{Discussion}

The analysis results show that the adaptability of the Water-Energy-Food System in the Yangtze River Delta fluctuates wildly. In order to minimize the negative impact of Socio-economic System on the Water-Energy-Food System, all regions in the Yangtze River Delta ought to continue to consolidate and enhance the adaptability, coordination and sustainability of the Water-Energy-Food System and following the "Yangtze River Delta Integration Strategy Requirements". Firstly, enhance the coordinated management of various departments and natural elements in the Yangtze River Delta and strengthen the links between various departments. It can ensure that the resource production and utilization of water, energy and food are controlled from a systematic point of view, in pursuit of coordinated development. Secondly, it's suggested to implement strict red lines for resource utilization and environmental protection. Regions of the Yangtze River Delta should optimize the layout and deployment of natural resources among industries. All regions need to strengthen the construction of ecological civilization and incorporate water quality, air quality, carbon emissions and other related indicators into the government 
assessment system. Furthermore, it's essential to strengthen the "three red lines" such as total water resources control and pollution control and ensure the smooth completion of the "3060 carbon target".

\section{Conclusions}

Based on Complex Adaptive Systems Theory, this paper constructs an analysis framework for adaptation between Socio-economic-natural system and the Water-Energy-Food System. We use the PSIR model to establish a Comprehensive Index Evaluation System for the adaptability of the Water-Energy-Food System. By interpreting the connotation of adaptability of the Water-Energy-Food System, we decompose it into the sensibility, stability, compatibility index and sustainability. We use the entropy method to assign weights to the criterion layer and indicator layer respectively and calculate quantitatively the adaptability of the Water-Energy-Food System in the Yangtze River Delta from 2010 to 2019. We systematically analyze temporal and spatial differentiation and influencing factors of the Water-Energy-Food System in the Yangtze River Delta, and draw the following conclusions.

Firstly, the adaptability of the Water-Energy-Food System in the Yangtze River Delta fluctuates greatly. The peak in 2018 was 0.7991 , while the trough in 2015 was only 0.2665 , accounting for only $33.35 \%$ of the highest value.

Secondly, the stability, sustainability, and compatibility of the Water-Energy-Food System in the Yangtze River Delta changes simultaneously, showing an overall "U-shaped" development trend. By contrast, sensibility shows an " $\mathrm{M}^{\prime}$-shaped development trend. Thirdly, there exist significant differences in the adaptability of the Water-Energy-Food System in the Yangtze River Delta. Zhejiang Province has the highest level of system adaptability of 0.8605 , while Anhui Province being the lowest at 0.70766 .

Finally, there exist significant differences in the sensibility, sustainability, compatibility and stability of regions in the Yangtze River Delta. For example, Shanghai has the strongest sensibility, while Anhui Province has the poorest stability among all regions. Finally, governments at all levels must establish an early warning mechanism for the risks of the Water-Energy-Food System as soon as possible and take measures to improve the adaptability of the Water-Energy-Food System according to local conditions. Shanghai should make full use of its technological advantages and capital advantages to optimize its industrial structure. Besides, it's necessary to limit the development of industries with high resource consumption and reduce reliance on foreign resources. Jiangsu is recommended to strengthen agricultural technology and equipment support and continue to improve the compatibility and stability of the Water-Energy-Food System. Zhejiang and Anhui should also increase the added value of regional resource utilization and promote sustainable economic and social development based on the matching situation of natural resources and industrial development.

Author Contributions: Z.H. conducted the model simulations and data analysis. H.M. conceived the research idea and co-wrote the paper. All authors have read and agreed to the published version of the manuscript.

Funding: This research was financially supported by Major Projects of the National Social Science Fund (No. 19ZDA084).

Institutional Review Board Statement: Not applicable.

Informed Consent Statement: Informed consent was obtained from all subjects involved in the study.

Data Availability Statement: The data presented in this study are available at http:/ / www.stats. gov.cn/tjsj/ndsj/, https:/ / data.cnki.net/trade/yearbook/single/n2019030257?z=z008, https:/ / data. cnki.net/area/Yearbook/Single/N2008070077?z=D20.

Conflicts of Interest: The authors declare no conflict of interest. 


\section{References}

1. Pena-Ramos, J.A.; Bagus, P.; Fursova, D. Water Conflicts in Central Asia: Some Recommendations on the Non-Conflictual Use of Water. Sustainability 2021, 13, 3479. [CrossRef]

2. Pena-Ramos, J.A.; Bagus, P.; Amirov-Belova, D. The North Caucasus Region as a Blind Spot in the "European Green Deal": Energy Supply Security and Energy Superpower Russia. Energies 2020, 14, 17. [CrossRef]

3. Elsharouny, M.R. Planning Coastal Areas and Waterfronts for Adaptation to Climate Change in Developing Countries. Procedia Environ. Sci. 2016, 34, 348-359. [CrossRef]

4. Porter, S. Evolution: Symbiont switching and environmental adaptation. Curr. Biol. 2021, 31, R1049-R1050. [CrossRef]

5. Rei, F.; Pinho, M.M.L. Paris Agreement and the Regions Adapt Initiave: The Role of Transnational Action in the Adoption and Implementation of Climate Policies. In Proceedings of the 2nd Energy, Environment and Sustainable Development Conference, Shanghai, China, 25-26 October 2017.

6. Badura, T.; Lorencová, E.K.; Ferrini, S.; Vačkářová, D. Public support for urban climate adaptation policy through nature-based solutions in Prague. Landsc. Urban Plan. 2021, 215, 104215. [CrossRef]

7. Change IPOC. Climate Change 2013-The Physical Science Basis; Cambridge University Press: Cambridge, UK, 2013.

8. Alfieri, L.; Feyen, L.; Di Baldassarre, G. Increasing flood risk under climate change: A pan-European assessment of the benefits of four adaptation strategies. Clim. Chang. 2016, 136, 507-521. [CrossRef]

9. Wilbanks, T.J.; Zimmerman, R.; Julius, S.; Kirshen, P.; Smith, J.B.; Moss, R.; Solecki, W.; Ruth, M.; Conrad, S.; Fernandez, S.J.; et al. Toward indicators of the performance of US Infrastructures under climate change risks. Clim. Chang. 2020, 163, 1795-1813. [CrossRef]

10. Sun, M.; Xu, X.; Wang, L.; Li, C.; Zhang, L. Stable energy, energy inequality, and climate change vulnerability in Pan-Third Pole regions: Empirical analysis in cross-national rural areas. Renew. Sustain. Energy Rev. 2021, 147, 111197. [CrossRef]

11. Zari, M.P.; Blaschke, P.M.; Jackson, B.; Komugabe-Dixson, A.; Livesey, C.; Loubser, D.I.; Gual, C.M.; Maxwell, D.; Rastandeh, A.; Renwick, J.; et al. Devising urban ecosystem-based adaptation (EbA) projects with developing nations: A case study of Port Vila, Vanuatu. Ocean Coast. Manag. 2020, 184, 105037. [CrossRef]

12. Wan, W.; He, D.; Li, X.; Xing, Y.; Liu, S.; Ye, L.; Yang, Y. Linking rare and abundant phoD-harboring bacteria with ecosystem multifunctionality in subtropical forests: From community diversity to environmental adaptation. Sci. Total Environ. 2021, 796, 148943. [CrossRef] [PubMed]

13. Gonçalves, C.; Honrado, J.P.; Cerejeira, J.; Sousa, R.; Fernandes, P.M.; Vaz, A.S.; Alves, M.; Araújo, M.; Carvalho-Santos, C.; Fonseca, A.; et al. On the development of a regional climate change adaptation plan: Integrating model-assisted projections and stakeholders' perceptions. Sci. Total Environ. 2022, 805, 150320. [CrossRef]

14. Jeong, H.; Kim, H.; Kim, H. Optimization Procedure for Climate Change Adaptation Investment Planning: Case of Flood Disaster Prevention in Seoul. J. Water Resour. Plan. Manag. 2020, 146, 04019077. [CrossRef]

15. Li, B.; Shi, Z.; Han, Z.; Tian, C. Spatial-temporal differences and influencing factors of the environmental adaptability of the human sea economic system in the Bohai Rim region. Acta Geogr. Sin. 2018, 73, 1121-1132.

16. Holbrook, N.J.; Johnson, J.E. Climate change impacts and adaptation of commercial marine fisheries in Australia: A review of the science. Clim. Chang. 2014, 124, 703-715. [CrossRef]

17. Dong, L.; Fang, C.; Cheng, Q.; Su, T.; Kou, K.; Kong, L.; Zhang, C.; Li, H.; Hou, Z.; Zhang, Y.; et al. Genetic basis and adaptation trajectory of soybean from its temperate origin to tropics. Nat. Commun. 2021, 12, 1-11.

18. Li, X.; Fang, C.; Yang, Y.; Lv, T.; Su, T.; Chen, L.; Nan, H.; Li, S.; Zhao, X.; Lu, S.; et al. Overcoming the genetic compensation response of soybean florigens to improve adaptation and yield at low latitudes. Curr. Biol. 2021, 31, 3755-3767. [CrossRef]

19. Huang, Y.; Huang, W.; Meng, Z.; Braz, G.T.; Li, Y.; Wang, K.; Wang, H.; Lai, J.; Jiang, J.; Dong, Z.; et al. Megabase-scale presence-absence variation with Tripsacum origin was under selection during maize domestication and adaptation. Genome Biol. 2021, 22, 1-28. [CrossRef] [PubMed]

20. Zhang, C.; Nong, X.; Shao, D.; Zhong, H.; Shang, Y.; Liang, J. Multivariate water environmental risk analysis in long-distance water supply project: A case study in China. Ecol. Indic. 2021, 125, 107577. [CrossRef]

21. Axelsson, C.; Giove, S.; Soriani, S.; Culligan, P.J. Urban Pluvial Flood Management Part 2: Global Perceptions and Priorities in Urban Stormwater Adaptation Management and Policy Alternatives. Water 2021, 13, 2433. [CrossRef]

22. Yokohata, T.; Iwahana, G.; Sone, T.; Saito, K.; Ishizaki, N.N.; Kubo, T.; Oguma, H.; Uchida, M. Projections of surface air temperature required to sustain permafrost and importance of adaptation to climate change in the Daisetsu Mountains, Japan. Sci. Rep. 2021, 11, 1-14.

23. Brockhaus, M.; Di Gregorio, M.; Djoudi, H.; Moeliono, M.; Pham, T.T.; Wong, G.Y. The forest frontier in the Global South: Climate change policies and the promise of development and equity. Ambio 2021, 50, 2238-2255. [CrossRef] [PubMed]

24. Cheng, Y.D.; Farmer, J.R.; Dickinson, S.L.; Robeson, S.M.; Fischer, B.C.; Reynolds, H.L. Climate change impacts and urban green space adaptation efforts: Evidence from U.S. municipal parks and recreation departments. Urban Clim. 2021, 39 , 100962. [CrossRef]

25. Zhou, H.; Han, X. Hidden Order: Adaptability Creates Complexity; Shanghai Science and Technology Education Press: Shanghai, China, 2000.

26. Zhi, Y.; Chen, J.; Wang, H.; Liu, G.; Zhu, W. Adaptability assessment of China's regional "water-energy-food" composite system from the perspective of symbiosis. China Popul. Resour. Environ. 2020, 30, 129-139. 
27. Qian, X.Y.; Liang, Q.M. Sustainability evaluation of the provincial water-energy-food nexus in China: Evolutions, obstacles, and response strategies. Sustain. Cities Soc. 2021, 75, 103332. [CrossRef]

28. Wang, Q.; Li, S.; He, G.; Li, R.; Wang, X. Evaluating sustainability of water-energy-food (WEF) nexus using an improved matter-element extension model: A case study of China. J. Clean. Prod. 2018, 202, 1097-1106. [CrossRef] 